One eminent legal light, to whom the question was referred, held that the expert was diatinctly the property of the side employing hin, and that his duty was simply to answer truth. fully the questions put to him, without attempting to enlighten the court upon facts known to him, but not brought out by the examination, no matter how vital such facts might be.

Another held that although the above course would be proper in a civil case, yet in a matter involving life and death the witness should insist upon the court becoming acquainted with his whole story. Do not such differences in legal opinion make it yet more desirable that the expert, at least in capital cases, should be the employee of the bench, rather than of the bar, in order that whatever investigations are made may be entirely open to public knowledge and criticism?

Drscussion.-Dr. Wiley: I hope that at some time in the future we shall be able to discuss this subject more fully. It is one which vitally interests most of us.

[CONTRIBUTIONS FROM THE ANALYTICAL LABORATORIES OF THE SCHOOL, of Mines, Columbia College.-No. 2.]

\title{
A NEW METHOD OF ANALYZING FATS AND RESINS.
}

By PARker C. MCIlhiNey, Ph.B., A. M. Received January 5, 1894.

$A$ number of processes have been proposed and used for the their unsaturated constituents to absorb by direct addition two or four atoms of bromine or iodine.

Allen, Analyst, 6, 177, proposed the use of an aqueous solution of sodium hypobromite to be added to a weighed quantity of the oil together with sufficient hydrochloric acid to liberate the bromine which then acts upon the oil. An excess having been added its amount is determined with sodium thiosulphate after adding potassium iodide.

Mills and Snodgrass, J. Soc. Chem. Ind., 2, 436 added a solution of bromine in carbon disulphide to a solution of the fat in the same solvent until an excess has been added as indicated by the red color of the bromine remaining permanent for fifteen 
minutes, and then a solution of potassium iodide and determined the excess with thiosulphate.

Mills and Akitt, $J$. Soc. Chem. Ind., 3, 65, proposed to substitute carbon tetrachloride for carbon disulphide and to deternine the excess by a solution of $\beta$ naphthol in the same solvent.

Hübl, Dingler's Poly. $J ., 253,281$, and $J$. Soc. Chem. Ind., 3, $64 \mathrm{r}$, suggested the use of a solution containing twenty-five grams of iodine and thirty grams of mercuric chloride dissolved in one liter of alcohol, a known measure of the reagent to be added to a weighed portion of the oil and allowed to remain tightly stoppered for a certain length of time when the excess is determined with thiosulphate.

Levallois, J.pharm. chim., $1887,1,334$, used bromine water, adding it, in just sufficient excess to slightly color the liquid, to the fatty acids obtained from the oil suspended in water.

Halphen, J. pharm. chim., I889, 20, 247, used bromine water in excess determining the amount of excess with sodium hydroxide.

Gantter, Ztschr. anal. chem., 1893, i78, suggested the use as a reagent of iodine dissolved in carbon tetracliloride.

The aim of all these processes is to determine the amount of halogen which the substance under examination will absorb by addition, but the figures obtained represent this only approximately even when substances which easily form substitution products are absent. Some substitution takes place with almost all oils, and with rosin oil, rosin, and probably most other resins, substitution causes the entire absorption.

The extent to which this substitution takes place depends upon the nature of the substance operated upon, and varies with different oils and resins, and a determination of the amount of halogen so absorbed may serve as a means of identifying and in some cases determining them.

The following process has been devised for determining the anount of bromine which oils and resins can absorb by addition, (which will be called the "Bromine Addition Figure"), and at the same time the amount of bromine which replaces hydrogen the action being allowed to continue eighteen hours in the dark; this gives the "Bromine Substitution Figure." The first figure 
gives in most cases the same information as the Hübl figure but is more reliable, while the second figure is a measure of the activity of the saturated constituents toward bromine.

It depends upon the fact that bromine in forming substitution compounds forms a molecule of hydrobromic acid for every atom of bromine which replaces hydrogen, while in forming additive compounds no hydrobromic acid is formed.

It was found impossible to use iodine alone as the addition figures are then very much too low and there is little difference between the substitution figures of bodies of unlike character.

The following solutions are used:

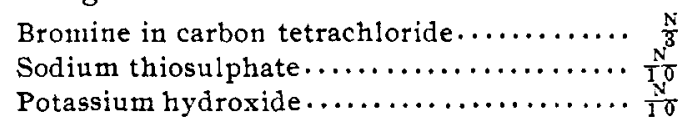

$0.250-1.000$ gram of the substance is dissolved in ten cc. of carbon tetrachloride in a bottle of $500 \mathrm{cc}$. capacity provided with a carefully ground glass stopper. An excess of bromine solution is added, the bottle tightly stoppered and placed in a dark closet. No water or alcohol should be present and light should be excluded as far as practicable. At the end of eighteen hours the bottle is cooled with ice to form a partial vacuum, and a piece of wide rubber tubing about one and one-half inches long is slipped over the lip of the bottle so as to form a well about the stopper. This well is filled with water and the stopper carefully lifted when the water will be sucked into the bottle and dissolve the hydrobromic acid present. When about twenty-five cc. of water have been added in this way, the bottle is well shaken and ro-20 cc. of twenty per cent. potassiun iodide solution added. The excess of bromine acts on the potassium iodide, liberating a corresponding amount of iodine which is titrated with $\frac{N}{10}$ thiosulphate after adding about seventy-five cc. more water, using starch as an indicator. The total bromine absorption is calculated from the difference between the amount of thiosulphate required for the bronrine solution added and the amount required for the excess. The contents of the bottle are now transferred to a separatory funnel and the aqueous portion separated, filtered through a cloth filter, a few drops of thiosulphate added if the solution is blue, and this is then titrated with $\frac{N}{I}$ potassium 
hydroxide using methyl orange as indicator. The end reaction is best observed by using a porcelain casserole to contain the solution, adding the alkali in slight excess and titrating back with $\frac{N}{10}$ hydrochloric acid until the pink acid tint just reappears. From the number of cubic centimeters of alkali used the amount of bromine present as hydrobromic acid is calculated. and when expressed in per cent. gives the bronine substitution figure because for every atom of bromine which has replaced an atom of hydrogen, one molecule of hydrobromic acid has been formed. Twice the bromine substitution figure subtracted from the total absorption gives the bromine addition figure.

The following results were obtained:

\begin{tabular}{|c|c|c|c|}
\hline Substance. & $\begin{array}{l}\text { Total bromine } \\
\text { absorptiont. } \\
\text { ighteen hours. }\end{array}$ & $\begin{array}{l}\text { Bromine. } \\
\text { addition } \\
\text { figure. }\end{array}$ & $\begin{array}{l}\text { Bromine } \\
\text { substitution } \\
\text { figure. }\end{array}$ \\
\hline W. G. Rosin .............. & .. 212.7 & 0.0 & 106.35 \\
\hline E. $\operatorname{Rosin} \ldots \ldots \ldots \ldots \ldots \ldots$ & . 206.5 & 0.0 & 103.25 \\
\hline Secoud run Rosin Oil (a).... & . I 16.2 & 0.0 & 5 S.1 \\
\hline$" \quad\|\quad\| \quad$ " $\quad$ (b) $\ldots$ & $\cdots+14.7$ & 0.0 & $57 \cdot 35$ \\
\hline American Raw Liuseed Oil .. & .. 102.88 & 102.88 & 0.0 \\
\hline Same Oil Boiled............ & $\cdots 103.93$ & 103.92 & 0.0 \\
\hline White Salad Cotton-seed Oi1. & $\therefore 65.54$ & 64.26 & 0.64 \\
\hline Sperm Oil ............... & 56.60 & $54 \cdot 5^{2}$ & {$[.04$} \\
\hline
\end{tabular}

A consideration of the above figures shows that the results are much more instructive than those obtained by the Hibl process which is the one in common use. Rosin oil, rosin, and other resins may be detected and determined in mixture with fatty oils, or, if they are present in known quantity, the character of the fatty oil may be determined. Investigations which are being made on a large number of oils and resins will probably furnish analytical data for the analysis of oils and varnishes.

\section{ON THE DETERMINATION OF PHOSPHORIC ACID.'}

BY H, VEMUERTON, JR,

I AST autumn I described a process for determining phosL phoric acid by titration of the ammonium phosphomolybdate with standard alkali. (This JouknaI, 15, 382.) The ratio

1 Read at the stated meeting of the Chemical Section of the Frauklin Institute, held Feuruary 20,1894 . 